\title{
UMA REFLEXÃO SOBRE MODIFICAÇÃO DE PRECEDENTES NA \\ PERSPECTIVA DA SEGURANÇA JURÍDICA
}

\section{A REFLECTION ON MODIFICATION OF PRECEDENTS FROM THE LEGAL SECURITY PERSPECTIVE}

Albino Gabriel Turbay Junior ${ }^{1}$

\begin{abstract}
RESUMO
Este artigo teve como objetivo promover uma reflexão sobre a modificação em precedentes judiciais na perspectiva da segurança jurídica. $\mathrm{O}$ método da pesquisa foi estudo bibliográfico. Para esta reflexão, primeiro foi realizada uma abordagem sobre sistemas da civil law e common law para a compreensão destes sistemas em relação aos precedentes e à segurança jurídica. Um sistema de precedentes e sua força vinculante é importante para a estabilidade e segurança jurídica, mas deve prever formas de modificação do pensamento jurídico para adaptar-se às transformações sociais. A segurança jurídica deve ser analisada em suas dimensões estática e dinâmica, garantindo estabilidade e confiabilidade, mas permitindo que o direito se mantenha adaptado à sociedade.
\end{abstract}

Palavras-chave: precedentes judiciais; superação de precedentes; segurança jurídica estática e dinâmica.

\begin{abstract}
This article aimed to promote a reflection on the change in judicial precedents from the perspective of legal certainty. The research method was a bibliographic study. For this reflection, first an approach on civil law and common law systems was carried out to understand these systems in relation to precedents and legal certainty. A precedent system and its binding force is important for legal stability and security, but it must provide for ways of modifying legal thinking to adapt to social changes. Legal security must be

\footnotetext{
${ }^{1}$ Doutor em Direito pela Instituição Toledo de Ensino - ITE/Bauru. Mestre em Direito pela Universidade Paranaense - UNIPAR. Professor da graduação e pós-graduação, integrante do corpo docente do Programa de Mestrado em Direito Processual e Cidadania na Universidade Paranaense - UNIPAR.
} 
analyzed in its static and dynamic dimensions, guaranteeing stability and reliability, but allowing the law to remain adapted to society.

Keywords: judicial precedents; overcoming precedents; static and dynamic legal security.

\section{INTRODUÇÃO}

O Código de Processo Civil publicado em 2015 promoveu avanços na construção de um sistema de precedentes judiciais, introduzindo possibilidade de força vinculante e buscando estabilidade, integridade e coerência na jurisprudência dos tribunais.

Há dispositivos no código indicando força vinculante em várias situações, em enunciados de súmulas, em acórdãos de incidentes por demandas repetitivas ou recursos repetitivos. Esta força vinculante se justifica para que a estabilidade esperada do sistema seja alcançada, promovendo previsibilidade, igualdade e segurança jurídica.

Mas é preciso reconhecer que, apesar do desejo de estabilidade e segurança, o direito não pode ficar alheio às mudanças e transformações que inevitavelmente ocorrem na sociedade e em suas relações. O direito não pode ficar isolado do meio em que é aplicado em razão do risco de deixar de atender às necessidades sociais e, com isso, deixar de ser efetivo.

A proposta deste artigo é promover uma reflexão sobre a relação entre a estabilidade gerada pela força vinculante dos precedentes e sua modificação adaptandose às transformações sociais, e a perspectiva da segurança jurídica.

Para uma melhor abordagem do tema será tratado de noções sobre os sistemas da common law e da civil law, da teoria do stare decisis, em seguida o foco será os precedentes e sua modificação por meio de técnicas de superação (alteração), por fim, a reflexão na perspectiva da segurança jurídica.

\section{NOÇÕES SOBRE O SISTEMA CIVIL LAW}

O sistema civil law é de origem romano-germânica e sua principal característica é a ideia de compilação e de codificação. Esta ideia veio do Direito romano preocupouse em racionalizar seu sistema jurídico por meio da cristalização dos textos jurídicos (normas consuetudinárias, normas escritas esparsas, decisões judiciais e a obra dos glosadores) que depois serviam para os estudos nas universidades e também como parâmetro para as futuras decisões (SOARES, 1999, p. 27). 
Importante ressaltar que o Direito chamado romano-germânico não é simplesmente uma continuação do Direito romano, mas sim uma evolução do que foi o Direito romano, pois não foi formado por meio de copiar o Direito romano, já que se utilizou de outras fontes diferentes do Direito romano (DAVID, 1998, p. 25).

O sistema romano-germânico surge no século XIII, na Europa Continental, sendo seu principal centro e passa por três fases: o período consuetudinário, o Legislativo e a sua expansão para fora da Europa (DAVID, 1998, p. 27).

Destaca-se como forma de fortalecimento do Direito romano a evolução do Direito na França. O Direito francês passou por três fases, Direito antigo, Direito intermediário e Direito napoleônico (RÁO, 2013, p. XX).

A primeira fase (Direito antigo) se caracteriza pelo uso dos costumes, do Direito romano, do Direito canônico e das ordenações reais. Em razão da invasão dos germanos o Direito romano vigorava no Sul e, no Norte, vigoravam os costumes germânicos, usando o Direito romano como fonte subsidiária, ressaltando que tais costumes se transformaram em Direito escrito (RÁO, 2013, p. 115).

O Direito canônico era utilizado porque questões como o casamento, filiação, testamento eram julgados pelas jurisdições eclesiásticas, bem como o Direito canônico influenciou as ordenações reais (RÁO, 2013, p. 115).

No Direito intermediário as leis civis tratavam de casamento, maioridade, propriedade.

Na fase do Direito napoleônico veio a ideia de unificação das leis civis (Código de 1804) com a consagração dos princípios inspiradores da Revolução Francesa. Mesmo com a queda de Napoleão, a legislação civil construída (código) permaneceu influenciando os sistemas jurídicos dos países anexados pelo poder da França, resultando na elaboração de códigos e legislações escritas e sua repercussão não apenas nos países que eram anexados, mas tomando a amplitude de seguir como uma forma de sistema jurídico a ser adotado por qualquer Estado.

Ressalta-se que o Direito germânico, apesar de ter em sua origem o uso de um Direito costumeiro, ao longo do processo histórico absorveu o Direito romano como forma de Direito escrito e, com o surgimento do Império e sua unificação política, foi elaborado um código civil que entrou em vigor em 1900, tendo como fonte o Direito romano e o Código Napoleônico (RÁO, 2013, p. 115). 
Assim, nota-se que as tendências de normas em textos escritos apontavam para a atividade legiferante, um caminho de leis escritas com uma sistematização de princípios gerais, evitando assim, o particularismo nas soluções jurídicas.

Neste sentido, o método interpretativo escolhido para o sistema civil law é o método dedutivo, o uso de silogismos, o que demonstrava uma maior preocupação com a organização do sistema, com rigor lógico, do que com as consequências da aplicação da norma jurídica.

Os defensores deste sistema usam como argumento a mensagem de segurança que passa a lei escrita e preexistente aos fatos, devendo os juízes seguir estas normas estabelecidas, com isso, estaria conforme a separação de poderes de Montesquieu.

Desta forma, afirma Guido Fernando Silva Soares (1999, p. 29):

\begin{abstract}
Na teoria de Montesquieu, qualquer veleidade de dar-se aos juízes o poder de fazer a lei seria ir contra o postulado da separação dos poderes. Reforça-se, assim, a concepção piramidal do Direito no sistema romano-germânico: o Judiciário é um poder que tem atributos dos mais amplos, não sendo controlado por nenhum dos outros dois, mas não tem iniciativa e seu poder é limitado pela res judicata; generalizações a partir de casos julgados só na matéria sub judice e sem qualquer possibilidade de criar precedentes, ou seja, de imporem-se a casos semelhantes no futuro, pela sua própria efetividade.
\end{abstract}

Na ideia central do sistema civil law a criação do Direito é feita pela atividade legislativa, assim, ao Poder Legislativo, composto por representantes do povo eleitos, cabe esta criação e aos juízes cabe, por silogismos, aplicar o Direito existente ao caso concreto.

\title{
3 NOÇÕES SOBRE O SISTEMA COMMON LAW
}

No estudo de René David (1998, p. 281) não foi só na Inglaterra que historicamente desenvolveu-se o sistema common law, porém, o Direito inglês constituiuse um modelo sobre este sistema.

Um dos fatores que contribuíram para o surgimento do sistema da common law foi a conquista da Normandia sobre a Inglaterra, fazendo com o feudalismo fosse instalado naquele país. O feudalismo é fruto da organização dos normandos para defender a conquista que tiveram, o conquistador fez a distribuição de modo que não houvesse nenhum grande feudo que pudesse confrontá-lo. Justamente esta organização que permite o desenvolvimento da common law (DAVID, 1998, p. 285). 
A ideia de common law vem do termo comuneley normanda. O objetivo era afastar a aplicação dos costumes locais para estabelecer uma lei comum em toda a Inglaterra, cabendo esta elaboração aos Tribunais Reais de Justiça (DAVID, 1998, p. 286).

Um dos principais pontos da common law é que o mais importante era o processo, o que a common law visava não era primordialmente a realização da justiça e sim, o meio processual para solucionar os casos levados às cortes. Além disto, era característica da common law a rejeição ao sistema do Direito romano-germânico (DAVID, 1998, p. 296).

O Direito inglês tem a divisão em: common law, statute law e equity. Conforme Vicente Ráo (2013, p. 146):

\begin{abstract}
A common law corresponde a um sistema de princípios e de costumes observados desde tempos imemoriais e aceitos, tacitamente, ou expressamente, pelo poder legislativo, revestindo ora caráter geral, quando vigoram em todas as jurisdições, ora caráter especial, quando imperam em certas regiões, tão somente.
\end{abstract}

A formação da common law é por meio do julgamento de casos concretos em que o Direito (comum) deve ser declarado, construindo jurisprudências que ficam registradas nos arquivos das Cortes e que adquirem força de precedentes obrigatórios para a solução de casos futuros.

O que se tem na common law é uma raiz pragmática e desvinculada de modelos abstratos, desta forma, verifica-se a utilização do método indutivo.

Conforme o estudo de Lenio Streck e Georges Abboud (2013, p. XX), “[...] o Direito inglês não é um Direito de universidades, nem um Direito dogmático, consiste em um Direito de processualistas e de práticos [...]".

Há uma discussão entre os pensadores do Direito se a common law é um Direito costumeiro ou um Direito jurisprudencial, os que entendem como Direito jurisprudencial têm como fundamento a construção do Direito por meio de decisões judiciais que depois tornam-se parâmetros (precedentes) para futuros casos a serem decididos pelos tribunais. Considere-se o fato de que este Direito fica escrito nas coletâneas das Cortes como norma escrita (RÁO, 2013, p. 146).

Apesar da discussão, é difícil desvincular as duas ideias, ou seja, o Direito comum é o resultado de padrões de condutas verificados na sociedade por meio dos 
costumes e que são consolidados como direito daquela sociedade por meio das decisões nos tribunais. Raó (2013, p. 148) confirma este entendimento:

\begin{abstract}
É certo que, com o acréscimo constante dos casos julgados, com a força de precedente obrigatório que deles resulta, o Direito comum, originariamente costumeiro, foi, aos poucos, se consolidando e, através das coletâneas de julgados, transformou-se numa particular espécie de Direito escrito, embora não ordenado, nem sistematizado.
\end{abstract}

O Direito norte-americano, historicamente e pela origem do país, filia-se ao Direito inglês, contudo há a diferença em razão da força da Constituição que exerce influência intensa em todo o Direito, tanto nas leis escritas quanto nas soluções do Direito comum. O que pode ser observado é que pela autonomia dos Estados alguns preservaram mais o Direito inglês (common law).

\title{
4 O COMMON LAW E O STARE DECISIS
}

É importante esclarecer de início que há diferença dos termos common law e stare decisis, pois é comum uma confusão entre os termos no sentido que seriam a mesma coisa e acabar concluindo que a tradição da common law sempre foi caracterizada pela obrigatoriedade dos precedentes, o que servirá para, adiante, estabelecer que a teoria dos precedentes e sua força vinculante não é a própria common law, assim, pode ser aplicada na civil law, como no sistema brasileiro (MARINONI, 2013, p.33).

No sentido de melhor organizar os precedentes no Direito inglês, em meados do século XVI, em substituição às compilações de decisões utilizadas, surgiram os chamados Law Reports, que formatavam os repertórios de decisões transcrevendo o caso e o respectivo julgamento, método que facilitava a busca de decisões anteriores para utilização como precedentes (TUCCI, 2004, p. 155).

Importante personagem nestes repositórios de decisões foi Edward Coke que exerceu a função de Chief Justice of the Common Pleas, considerado o fundador da teoria moderna do precedente judicial publicou 11 volumes de repertórios, buscando a preservação do que foi construído em termos de conhecimento jurídico e seus princípios por juízes do passado, o que além de conservar conhecimento, estes repositórios garantiam a certeza da utilização adequada dos princípios construídos (TUCCI, 2004, p. $155)$. 
A atividade de Coke, promovendo a classificação e estruturação dos precedentes, contribuiu para verificar o sentido das decisões, se eram no mesmo sentido ou divergentes, bem como, concluir qual era a ratio decidendi para a adequada citação do precedente, mas é necessário esclarecer que até o século XVIII estes repositórios conhecidos como Law Reports eram particulares, o que facultava aos juízes acolherem ou não como precedente judicial (TUCCI, 2004, p. 156-157).

Percebe-se, assim, que era traçado um caminho para a obrigatoriedade dos precedentes, mas ainda, tal fenômeno não acontecia justamente por ser facultado ao juiz acatar um precedente. Contudo, nas primeiras décadas do século XIX a força vinculante do precedente judicial foi reconhecida pela corte inglesa (House of Lords). Conforme José Rogério Cruz e Tucci (2004, p. 158):

\footnotetext{
Na decisão do caso Beamisch vs. Beamisch, conduzida, em 1861, pelo Lord Campbell, ficou virtualmente estabelecido que a House of Lords estaria obrigada a acatar a sua própria autoridade proclamada nos julgamentos: '[...] o Direito declarado na ratio decidendi, sendo claramente vinculante para as cortes inferiores e todos os súditos do reino, se não fosse considerado igualmente vinculante para os Law Lords, a House of Lords se arrogaria o poder de alterar o Direito e legiferar com autônoma autoridade'.
}

Nota-se no final do trecho acima a intenção de vincular a própria corte aos seus precedentes, pois era natural que os precedentes vinculavam os tribunais inferiores, por hierarquia, mas a discussão agora era a vinculação em relação ao próprio tribunal que criou o precedente.

Ainda, esclarece o referido pensamento que a não vinculação para a própria corte superior (House of Lords) seria interpretada como a possibilidade de "se arrogar" e atuar como poder legiferante. Assim, já se tinha na construção dos precedentes um cuidado com a separação dos poderes.

Deve ficar registrado, porém, que a própria House of Lords já havia declarado, no caso Bright vs. Hutton, que poderia fazer correções de suas decisões se entendessem ter ocorrido erros (TUCCI, 2004, p. 158).

Com isto, pode ser concluído que na história do Direito inglês e na estruturação da teoria dos precedentes, com o tempo foi introduzido a teoria de sua força vinculante, bem como, entendeu-se que esta força vinculante poderia ser excepcionada em determinadas situações. 
José Rogério Cruz e Tucci (2004, p. 159) demonstra que a própria corte entendeu que os pensamentos jurídicos apresentados nas decisões passadas (precedentes) deveriam ser revistos respeitando a evolução daqueles pensamentos:

\begin{abstract}
Segundo consta, a House of Lords exerceu pela primeira vez essa prerrogativa uma centúria depois, somente em 26 de julho de 1966, ocasião em que o Chanceller Lord Gardner proclamou, em nome de todos os componentes da corte, em uma resolução específica - Practice Statement of Judicial Precedent que era prudente rever orientação emitida no passado, quando parecesse correto: 'Os Law Lords consideram o uso do precedente em indispensável fundamento para determinar o Direito e sua aplicação aos casos individuais. Este fornece pelo menos um grau de certeza sobre o qual os cidadãos podem nortear a conduta dos próprios negócios, e também uma base para o desenvolvimento ordenado das regras legais. Os Law Lords, todavia, reconhecem que a adesão muito rígida ao precedente pode trazer injustiças em certos casos, e ainda restringir indevidamente a evolução futura do Direito. A despeito de ser normalmente vinculante um precedente pronunciamento da House of Lords, os seus integrantes propõem modificar a praxe atual, podendo superar uma precedente decisão quando pareça oportuno' ('[...] when it appears right to do so').
\end{abstract}

A possibilidade de superação do precedente (overruling), uma inovação na teoria do stare decisis, teve seu primeiro caso registrado no ano de 1968 e, apesar de ter sido pouco utilizado neste período era o mecanismo que facilitaria a evolução do Direito (TUCCI, 2004, p. 159).

Desta forma, a moderna teoria do stare decisis possui três características essenciais: a primeira, da força vinculante dos precedentes em relação aos tribunais inferiores; a segunda, da força vinculante ao próprio tribunal que construiu o precedente; e a terceira, da possibilidade de superação do precedente para a evolução do Direito.

\title{
5 OS PRECEDENTES E SUA MODIFICAÇÃO
}

Antes de tratar especificamente sobre precedentes e sua modificação por meio de técnicas de superação é preciso esclarecer dois pontos.

O primeiro é de que o sistema de precedentes estabelecido pelo Código de Processo Civil não é o mesmo originado no sistema da common law. Há uma discussão doutrinária se houve ou não uma aproximação entre os sistemas civil law e common law, bem como conclusões no sentido de que não há mais sistemas puros.

O fato é que o Código de Processo Civil promoveu uma valorização no sistema de precedentes, especialmente nos artigos 926 e 927, mas esta valorização pode ser também constatada nos artigos 311 (tutela de evidência), 332 (improcedência liminar do pedido). 
Outro ponto é que nosso código processual trabalha com vários termos, jurisprudência, precedentes, enunciados de súmula, súmula vinculante, acórdãos em recursos repetitivos e demandas repetitivas, e não está claro qual a diferença de tratamento entre eles, por exemplo, os conceitos e se todos podem ter força vinculante.

Não é objetivo deste artigo discutir sobre a aproximação dos sistemas ou a diferença entre os termos, até porque o artigo $926^{2}$ do Código de Processo Civil deixa claro a interação entre jurisprudência, enunciados de súmula e precedentes, fazendo parte do mesmo sistema de uniformização.

Neste sentido, o termo precedente será utilizado de forma genérica com a ideia de força vinculante e obrigatoriedade, de uma jurisprudência, enunciado de súmula, precedentes ou acórdãos em demandas ou recursos repetitivos.

O que importa para este artigo é que a formação de um precedente e sua força vinculante trazem um sentido de estabilidade, previsibilidade e igualdade. Nos termos do artigo 926 do CPC, os Tribunais devem manter a estabilidade, integridade e coerência do sistema.

A previsibilidade das decisões, característica dos precedentes, assim, característica da common law, acaba por ser situação mais concreta do que a previsibilidade das leis, já que na civil law há uma hiperinflação de leis e acaba interferindo no conhecimento destas leis. Ainda, deve ser levado em consideração que as leis são interpretadas, neste sentido, quando ocorrem diferentes interpretações da lei, o que garante a previsibilidade é a uniformização da jurisprudência ou a formação de precedentes que uniformiza esta interpretação e não a própria lei (MARINONI, 2013, p.123).

A utilização dos precedentes garante a estabilidade pela continuidade por um mínimo de tempo de aplicação no mesmo sentido, evitando direções variadas de entendimento a todo momento.

No caso de juízes que se entendem como autônomos e não vinculados aos precedentes não acontece esta estabilidade e quem se prejudica é o jurisdicionado. Por isso a importância e necessidade de uma estabilidade por meio dos precedentes.

\footnotetext{
${ }^{2}$ Art. 926. Os tribunais devem uniformizar sua jurisprudência e mantê-la estável, íntegra e coerente. $\S 1^{\circ}$ $\mathrm{Na}$ forma estabelecida e segundo os pressupostos fixados no regimento interno, os tribunais editarão enunciados de súmula correspondentes a sua jurisprudência dominante. $\$ 2^{\circ}$ Ao editar enunciados de súmula, os tribunais devem ater-se às circunstâncias fáticas dos precedentes que motivaram sua criação.
} 
Em relação ao duplo grau de jurisdição se fosse analisar a lógica da civil law não haveria esta submissão da decisão a um segundo juízo, pois se o juiz somente aplica a lei a previsibilidade seria inevitável. Contudo, o juiz pode não aplicar a lei adequadamente o que justifica o duplo grau.

O sistema do duplo grau e a independência do juiz singular decidir sem se vincular às decisões superiores, resulta em um sistema de descrédito do juiz de primeiro grau, pois não importando o que ele decidir o que valerá é a decisão do tribunal (MARINONI, 2013, p. 131).

Mas a ideia de precedente e seu stare decisis ajuda na credibilidade do Judiciário e na segurança jurídica, pois haverá decisões diversas somente nas situações diferentes, o que garante a estabilidade do próprio sistema judiciário. Por outro lado, não ter certeza nas decisões gera desconfiança e insegurança.

É importante estabelecer a diferença entre a coisa julgada e o precedente. Em comum os dois geram a ideia de estabilidade, por isso, de segurança. A Coisa julgada é diferente de precedente, pois a coisa julgada é uma forma de garantir a irretroatividade de leis contra decisões já realizadas, e o sistema de precedentes garante decisões iguais em casos iguais e a condição da previsibilidade. Mesmo em coisa julgada erga omnes não há a confusão com os precedentes, pois a coisa julgada significa a inalterabilidade da aplicação do Direito e os precedentes à estabilidade desta aplicação (MARINONI, 2013, p. 137).

Após a formação dos precedentes, para que eles não se perpetuem injustificadamente, há técnicas de alteração (superação), conforme a situação que provoque esta alteração. As técnicas de alteração têm missão relevante, pois, mesmo com a ideia de estabilidade e previsibilidade os precedentes precisam se adaptar à evolução do Direito e da sociedade.

A elaboração de novos raciocínios jurídicos, de novos pensamentos e assim, a consequente revogação ou superação de posicionamentos jurisprudenciais e precedentais, não representa um afastamento do sistema de precedentes obrigatórios (PORTES, 2012, p. 189).

A revogação ou alterações de precedentes visa promover correções de teses jurídicas que foram elaboradas incorretamente ou que se tornaram inadequadas em razão das mudanças que se operam na sociedade.

A manutenção ou alteração de um precedente depende de sua congruência social e de sua consistência sistêmica, ou seja, a tese jurídica que fundamenta o precedente deve 
estar conforme os valores da sociedade, assim, repercutir na confiança que os jurisdicionados têm no Direito proposto. Ainda, a tese jurídica não pode ser contraditória ao sistema jurídico e sua carga doutrinária (conceitos e institutos) que fundamenta as escolhas jurídicas nas soluções dos casos (PORTES, 2012, p. 192-193).

Desta forma, quando se nota no sistema de precedentes um conflito com a congruência social ou de inconsistência sistêmica é preciso promover alterações, mesmo que ocorra uma ponderação entre a necessidade de adequação e a estabilidade do sistema, utilizando técnicas de sinalização para posterior alteração.

Basicamente há o distinguishing e o overruling, que são respectivamente a ideia de casos distintos e a revogação dos precedentes, mas a partir destes mecanismos podem ocorrer outras situações.

Quando ocorrer de casos em que as situações fáticas sejam diferentes, o que impede a aplicação da mesma ratio, surge a figura do distinguishing. Nesta hipótese, o caso atual tem peculiaridades que o torna diferente do caso precedente, merecendo assim, tratamento diferente.

Por isso, é importante que no caso precedente tenha ocorrido a delimitação de sua ratio, definindo suas circunstâncias fáticas e sua proposição jurídica, assim, não há o risco de que o precedente seja aplicado a casos diferentes e consequentemente, possibilitando a técnica do distinguishing (PORTES, 2012, p. 197).

Importante dizer que o distinguishing, que expressa a distinção entre casos para averiguar a aplicação de um precedente ou não, não é uma questão que o precedente é uma bad law, mas é um problema de inaplicabilidade do precedente por distinção dos casos (MARINONI, 2013, p. 326).

Sobre o distinguishing é importante verificar se as distinções são de fatos fundamentais ou não, pois se os fatos não são fundamentais, conforme a decisão que gerou o precedente, não é caso de se afastar tal precedente, pois a essência é igual. Esta distinção fática deve revelar uma justificativa para a não aplicação do precedente.

Nota-se que quando o precedente se torna very distinguished, é sinal do enfraquecimento de sua autoridade, o que pode inclusive causar sua revogação.

Um novo fato, como distinguishing pode gerar a alteração do precedente, em razão de um fato ainda não previsto, ou anteriormente não previsto, mas isto só é viável se não houver compatibilidade com o precedente.

A distinção pode gerar uma ampliação ou redução do precedente, configurando uma correção ou acomodação da ratio decidendi, mas uma distinção inconsistente impede 
de revogar o precedente em razão da estabilidade e da segurança, podendo surgir uma ideia de provisoriedade do precedente (MARINONI, 2013, p. 332).

Mas este alcance amplo ou limitado só pode ser visto se confrontado com novos casos, com a ponderação entre as razões do precedente e os valores que justificam o sistema, como segurança, previsibilidade e igualdade.

Esta segurança, previsibilidade e igualdade demonstra a confiança do sistema, sendo que em situações de perda de consistência do precedente é possível a chamada técnica de sinalização ao invés da revogação.

Esta técnica permite que a sociedade e, em especial, os advogados que informam seus clientes sobre direitos, possam se preparar para uma futura revogação do precedente, justamente em razão de sua perda de consistência, desta forma se protege a confiança no sistema (MARINONI, 2013, p. 335).

É importante fazer uma referência à chamada distinção inconsistente, pois esta gera algumas discussões no sistema de precedentes já que coloca em jogo a integridade dos precedentes, pois o que deveria acontecer é a aplicação consistente, a revogação, a ampliação do alcance ou até mesmo a distinção.

Contudo a distinção inconsistente pode ser positiva no sentido de provisoriedade e de demonstrar que o precedente está perdendo força, importante para o conhecimento dos jurisdicionados e sua confiança no sistema já que tomam ciência da possibilidade de uma alteração.

O chamado overruling, é a revogação total dos precedentes, sendo apresentadas razões para não seguir o precedente e para a construção de nova tese jurídica. No distinguishing o precedente não se conforma ao caso atual, no overruling há a revogação (PORTES, 2012, p. 198).

O overruling tem a ideia de reavaliação dos fundamentos que formaram o precedente, cancelando a interpretação anterior e formulando uma nova interpretação para ser aplicada como precedente (CAMARGO, 2012, p. 569).

Assim, poderia dar, a princípio, a ideia de instabilidade no sistema de precedentes, contudo, ao contrário, seu significado é de estabilidade dos valores sociais, pois se um precedente que se afastou destes valores se manter no sistema ele resultará na inconsistência de decisões presentes e, neste caso, gerará a instabilidade.

Desta forma, a revogação deve ocorrer quando necessária e quando deixar de haver congruência entre as aspirações sociais e o precedente. O Direito não pode ficar estático em nome de uma confiabilidade ou estabilidade, pois esta estabilidade estaria 
prejudicada por manutenção de precedentes que se afastam da realidade social (MARINONI, 2013, p. 388 e ss).

O que não pode acontecer é a surpresa, esta sim quebra a confiança do sistema, por isso importantes as críticas doutrinárias aos precedentes e sua ratio e as técnicas de distinções inconsistentes, pois vão chamado a atenção para uma possível alteração e preparando a sociedade e os advogados para este resultado. O que afirma a necessidade e a legitimidade da revogação.

Em relação aos efeitos, o overruling, pode ter efeitos pretéritos (retrospective effects) ou efeitos para o futuro (prospective effects), quando tem efeitos pretéritos o precedente atinge um caso em um momento em que o precedente ainda não estava formado, podendo questionar sobre o prejuízo de uma conduta que aconteceu anterior ao pensamento jurídico. No caso de efeitos para o futuro o tribunal indica um marco temporal futuro para o precedente surtir efeitos (CAMARGO, 2012, p. 571).

Outra técnica é a transformation que é a técnica de transformar o precedente a partir de nova decisão sem revogá-lo. A transformation faz uma acomodação do precedente sem importar em assumir erro de fundamentação, diferente do overruling já que neste se opera a revogação, mesmo que parcial (MARINONI, 2013, p. 342).

A vantagem da transformation está na preservação da confiabilidade do sistema, mas a desvantagem está no fato que os tribunais inferiores têm mais dificuldade para entender esta transformação, sendo que esta falta de compreensão pode se agravar com várias transformações em um mesmo precedente.

Há, ainda, o overriding que se assemelha à revogação parcial, mas ele não interfere no entendimento anterior, como se fosse um novo entendimento do caso, mas com a desvinculação do novo caso para aplicar um entendimento mais recente, ou seja, muda o entendimento, mas não interfere no entendimento anterior.

A técnica do anticipatory overruling em que as cortes antecipam a não utilização de precedentes tem como fundamentos o desgaste do precedente, a tendência da Suprema Corte pela revogação e a espera pelo caso apropriado para revogação e ainda, alteração na composição da Suprema Corte, inconsistência do precedente e a percepção da quebra dos efeitos práticos dos precedentes. Importante salientar que as cortes de Apelação visualizando a revogação pela Suprema Corte acabam deixando de aplicar um precedente, já que a sinalização justificaria a não aplicação de um precedente em via de ser revogado, sendo que sua manutenção poderia incorrer em injustiça (MARINONI, 2013, p. 401 e Ss.). 
O artigo $927^{3}$ do Código de Processo Civil em seu $\$ 4^{\circ}$ exige que a modificação de um precedente seja devidamente fundamentada, de forma específica, em razão dos princípios da segurança jurídica, da proteção da confiança e da isonomia. Este dispositivo demonstra que há limitações no poder dos juízes e tribunais em promover modificações nos precedentes, assim, apesar das técnicas de alteração ou superação encontradas na doutrina e utilizadas pelos tribunais não há um consenso sobre a utilização adequada de tais técnicas, por exemplo, uma discussão é importante: apenas os tribunais que construíram o precedente podem promover sua alteração, ou qualquer juiz ou tribunal inferior pode promover discordância de teses e julgar de forma diferenciada de um precedente vinculante?

Daniel Mitidiero (2016, p. 120-121) entende que apenas o tribunal que foi responsável pela formação do precedente pode promover seu afastamento, em suas palavras “[...] apenas o Supremo Tribunal Federal pode se afastar de seus precedentes constitucionais e o Superior Tribunal de Justiça de seus precedentes federais."

No mesmo sentido, apenas o próprio tribunal estadual ou regional poderia realizar a modificação de sua jurisprudência vinculante, não podendo ser modificada pelos juízes de primeiro grau.

Para o referido autor o afastamento de precedentes por tribunais inferiores ou juízes equivale há uma desobediência a hierarquia judiciária, quebrando a organização na estrutura do Poder Judiciário, com isso, é preciso respeitar a regra do stare decisis que não pode ser violada pela discordância de juízes que tem a obrigação de seguir o precedente (MITIDIERO, 2016, p. 121).

Contudo, Daniel Mitidiero, reconhecendo a liberdade de manifestação de pensamento em um Estado Democrático, vê como alternativa a possibilidade de que o dissentimento com o precedente possa ser manifestado como opinião na redação da decisão, e completa que: "trata-se de solução que pode inclusive servir como um bom parâmetro para aferição do grau de aprovação do precedente e eventualmente como elemento capaz de indicar o desgaste e necessidade de sua superação" (2016, p. 125).

De fato, a alternativa é interessante frente às incertezas sobre modificações de precedentes. É importante que o sistema processual brasileiro encontre um caminho para

\footnotetext{
${ }^{3} \S 4^{\circ} \mathrm{A}$ modificação de enunciado de súmula, de jurisprudência pacificada ou de tese adotada em julgamento de casos repetitivos observará a necessidade de fundamentação adequada e específica, considerando os princípios da segurança jurídica, da proteção da confiança e da isonomia.
} 
que a construção de precedentes, sua estabilidade e sua superação tenham equilíbrio para a credibilidade do sistema, neste sentido, deve haver regras limitando as modificações com olhar na segurança jurídica, o que será debatido no próximo tópico.

\section{A SEGURANÇA JURÍDICA E A MODIFICAÇÃO DE PRECEDENTES}

A segurança é uma necessidade na vida em sociedade, pois, cada cidadão precisa se organizar, planejar, direcionar sua vida conforme as regras da sociedade em que vive, saber seus direitos e deveres.

O Estado de Direito tem a segurança jurídica como uma garantia, ou seja, garantia de estabilidade, continuidade da ordem jurídica e previsibilidade das consequências jurídicas, sendo um princípio fundamental ao sistema democrático.

Canotilho tem a ideia de um princípio geral da segurança jurídica, por este princípio o indivíduo tem o direito de poder confiar (princípio da proteção da confiança) que seus atos e relações jurídicas serão realizados de acordo com as normas vigentes e as decisões que incidem sobre seus direitos, conhecendo também os efeitos jurídicos das normas e decisões (CANOTILHO, 2003, p. 257).

Apesar de não estar expressa na Constituição Federal, a segurança jurídica é encontrada nos casos do princípio da legalidade, o direito adquirido, a coisa julgada, o ato jurídico perfeito, anterioridade em matéria penal e irretroatividade da lei penal prejudicial.

Desta forma, é possível falar-se em segurança jurídica tanto em relação aos atos normativos elaborados e impostos pelo Estado por intermédio do Legislativo, as leis, quanto aos atos jurisdicionais, as decisões judiciais.

A segurança jurídica deve refletir a necessidade de uma ordem jurídica estável, para isso, dois elementos são importantes, a univocidade em relação à qualificação das situações jurídicas e a previsibilidade das consequências da conduta (MARINONI, 2013, p. 121).

Os temas, segurança jurídica e modificação de precedentes, não são contraditórios, pelo contrário, são complementares, pois a estabilidade gerada pelos precedentes, como já foi dito, precisa acompanhar a evolução e transformações do meio social, assim o direito precisa evoluir.

Analisando a tensão existente entre a evolução do Direito e a estabilidade da jurisprudência, Tereza Arruda Alvim Wambier (2012, p. 15) argumenta que, apesar da necessidade de adaptar-se à uma sociedade e suas mudanças, não se justifica alterações 
na jurisprudência "da noite para o dia", é necessária uma composição entre previsibilidade e adaptabilidade.

O que fundamenta a interação entre estabilidade e previsibilidade dos precedentes, segurança jurídica e possibilidade de modificação dos precedentes para acompanhar as transformações sociais, é a visão de segurança jurídica sob duas dimensões, a estática e a dinâmica.

Conforme Humberto Ávila (2012, p. 296):

\begin{abstract}
A dimensão estática diz respeito ao problema do conhecimento do Direito, ao seu saber, ou à questão da comunicação no Direito, e revela quais são as qualidades que ele deve possuir para que possa ser considerado "seguro" e, com isso, possa servir de instrumento de orientação ao cidadão, em geral, e ao contribuinte, em especial. Nesse aspecto, o Direito deve ser compreensível e efetivo.
\end{abstract}

O direito ser compreensível significa que o cidadão deve conhecer o direito, pois, para obedecer aos comandos de condutas determinados pelo direito cada cidadão precisa agir a partir deste conhecimento. Neste sentido, o direito precisa ser inteligível e acessível, tornando-se depois efetivado (ÁVILA, 2012, p. 296-297).

Humberto Ávila (2012, p. 297) complementa com ideia de que a segurança estática deve alcançar "segurança de vigência", "segurança de suficiência" e "segurança de significado", com isso, a norma a ser seguida reflete segurança a partir do conhecimento de sua vigência, de sua clareza e de seu conteúdo.

A outra dimensão da segurança jurídica é a dimensão dinâmica:

\begin{abstract}
A dimensão dinâmica, a seu turno, refere-se ao problema da ação no tempo e prescreve quais são os ideais que devem ser garantidos para que o Direito possa "assegurar" direitos ao cidadão e, com isso, possa servir-lhe de instrumento de proteção. Nesse sentido, o Direito deve ser confiável e calculável. (ÁVILA, 2012, p. 297)
\end{abstract}

A dimensão dinâmica tem a ver com o tempo, passado, presente e futuro, e as modificações que podem ocorrer no direito. Neste sentido, sendo inevitável modificações, é preciso que estas modificações não afetem o direito do cidadão de forma a retirar a confiabilidade.

Para Humberto Ávila (2012, p. 297): “Confiável, no sentido de permitir que o cidadão possa saber quais as mudanças que podem ser feitas e quais as que não podem ser realizadas, evitando que seus direitos sejam frustrados". Esta confiabilidade implica em 
proteger situações já concretizadas, em garantir a durabilidade do ordenamento jurídico e ter regras sobre irretroatividade das normas.

A ideia do calculável é "[...] no sentido de permitir que o cidadão possa saber como as mudanças podem ser feitas e quando elas serão realizadas, impedindo que ele seja surpreendido" (ÁVILA, 2012, p. 298).

É importante esta percepção da estabilidade e segurança do ordenamento jurídico e sua relação com o tempo, pois a construção das normas jurídicas é um reflexo da relação passado-presente-futuro. Esta relação não é apenas formal, deve ser material, o que será estabelecido no futuro do ordenamento jurídico deve respeitar o que foi construído no passado e as vivências do presente, numa ideia de transição.

Conforme Humberto Ávila (2012, p. 301): “Essas considerações permitem dizer que o princípio da segurança jurídica visa, na dimensão dinâmica, a garantir a respeitosa transição do passado ao presente e do presente ao futuro por meio do conhecimento do Direito".

Nesta linha, é preciso que o sistema de precedentes vinculantes (jurisprudência, enunciados de súmula, decisões ou precedentes), possa garantir a confiança dos cidadãos com sua estabilidade e previsibilidade, mas ao mesmo tempo, é preciso que esteja aberta para as mudanças da sociedade.

O equilíbrio é importante, por isso, em um sistema de precedentes vinculantes são necessárias regras sobre técnicas de superação que sejam flexíveis o suficiente para não promover um engessamento no pensamento jurídico, mas, que estas regras estabeleçam limitações que garantam a confiabilidade do ordenamento jurídico, protegendo os direitos das pessoas.

\section{CONCLUSÃO}

A reflexão proposta no início da pesquisa proporcionou uma visão geral sobre a importância de um sistema de precedentes e da sua força vinculante. Um sistema com estas características tem o mérito de dar estabilidade no ordenamento jurídico, com isto, promove previsibilidade, igualdade e segurança na aplicação das normas jurídicas.

Mas é preciso compreender que ao mesmo tempo que o sistema busca por estabilidade, previsibilidade e igualdade, a sociedade está em contínua transformação e, assim, a solução jurídica para uma relação pode mudar a partir desta dinâmica social, o direito precisa adaptar-se na mesma proporção. 
Entre estabilidade, modificação e segurança não há uma contradição, a relação deve ser vista pelo prisma das dimensões estática e dinâmica da segurança jurídica e a relação entre a sociedade e o tempo e a transição entre o passado, o presente e o futuro.

A partir de inevitáveis modificações é importante que o ordenamento jurídico e seu sistema de precedentes construam regras sobre técnicas de superação e suas limitações, promovendo um equilíbrio entre a necessária estabilidade e estas modificações relevantes para a sociedade, garantindo a fluência do direito e a devida segurança jurídica em suas dimensões.

\section{REFERÊNCIAS}

ÁVILA, Humberto. Segurança jurídica: entre permanência, mudança e realização do direito tributário. $2^{\mathrm{a}}$ Ed. São Paulo: Malheiros Editores, 2012.

ABBOUD, Georges; STRECK, Lenio Luiz. O Que é Isto?: o precedente judicial e as súmulas vinculantes. Porto Alegre: Livraria do Advogado, 2013.

CAMARGO, Luiz Henrique Volpe. A Força dos Precedentes no Moderno Processo Civil Brasileiro. In: WAMBIER, Tereza Arruda Alvim. Direito Jurisprudencial. São Paulo: Revista dos Tribunais, 2012.

CANOTILHO, José Joaquim Gomes. Direito Constitucional e Teoria da Constituição. $7^{\text {a }}$ ed. Coimbra: Livraria Almedina, 2003.

DAVID, René. Os Grandes Sistemas do Direito Contemporâneo. $3^{\mathrm{a}}$ ed. Tradução de Hermínio A. Carvalho. São Paulo: Martins Fontes, 1998.

MARINONI, Luiz Guilherme. Precedentes Obrigatórios. $3^{\text {a }}$ ed. São Paulo: Revista dos Tribunais, 2013.

MITIDIERO, Daniel. Precedentes: da persuasão à vinculação. São Paulo: Editora Revista dos Tribunais, 2016.

PORTES, Maira. Instrumentos para Revogação de Precedentes no Sistema de Common Law. In: MARINONI, Luiz Guilherme (org.). A Força dos Precedentes: estudos dos cursos de mestrado e doutorado em direito processual civil da UFPR. $2^{\mathrm{a}}$ ed. Salvador: JusPodivm, 2012.

RÁO, Vicente. O Direito e a Vida dos Direitos. $7^{\text {a }}$ ed. São Paulo: Revista dos Tribunais, 2013. 
SILVESTRE, Gilberto Fachetti; BORGES, Carolina Biazatti; BENEVIDES, Nauani Schades. THE APPLICATION OF THE DYNAMIC THEORY OF THE BURDEN OF PROOF IN CIVIL MATTER AFTER THE VALIDITY OF THE CODE OF CIVIL PROCEDURE OF 2015: AN ANALYSIS OF DECISIONS. Revista Juridica, [S.1.], v. 1, n. 58, p. 137 - 158, abr. 2020. ISSN 2316-753X. Disponível em: <http://revista.unicuritiba.edu.br/index.php/RevJur/article/view/3827/371372168>.

Acesso em: 23 abr. 2020. doi:http://dx.doi.org/10.21902/revistajur.2316753X.v1i58.3827.

SOARES, Guido Fernando Silva. Commom Law: introdução ao direito dos EUA. São Paulo: Revista dos Tribunais, 1999.

TUCCI, José Rogério Cruz e. Precedente Judicial como Fonte do Direito. São Paulo: Revista dos Tribunais, 2004.

WAMBIER, Tereza Arruda Alvim. Precedentes e Evolução do Direito. In: WAMBIER, Tereza Arruda Alvim (org.). Direito Jurisprudencial. São Paulo: Revista dos Tribunais, 2012. 